\title{
Distinguishing benchmarks of biological status from management reference points: A case study on Pacific salmon in Canada
}

\author{
CARRIE A. HOLT* AND JAMES R. IRVINE \\ Fisheries and Oceans Canada, Pacific Biological Station, 3190 Hammond Bay Road, Nanaimo, British Columbia \\ V9T 6N7, Canada \\ Date submitted: 9 November 2012; Date accepted: 25 April 2013; First published online: 18 June \\ 2013
}

\section{SUMMARY}

For fisheries with multiple, competing objectives, identifying and applying reference points for management can present difficult trade-offs between long-term biological and shorter-term socioeconomic considerations. The term biological benchmarks is proposed to demarcate zones of population status based on conservation and production considerations. These scientifically derived benchmarks contrast with management reference points that generally require additional shorter-term socioeconomic information best obtained through public consultations. This paper illustrates the distinction between biological benchmarks and management reference points with a case study on Pacific salmon (Oncorhynchus spp.). In Canada, the management and assessment of wild Pacific salmon are guided by a major 2005 conservation policy, which calls for the identification of biological benchmarks to categorize status of demographically isolated populations, and decision-support tools, such as management reference points, to integrate biological information with appropriate social and economic information. In the Fraser River (British Columbia, Canada), the selection of management reference points for sockeye salmon (O. nerka) fisheries explicitly considered trade-offs between the probability of meeting long-term biological objectives on component populations and harvest objectives on population aggregates. Decisions about reference points were made in a consultative process that included extensive stakeholder engagement. Other agencies are urged to distinguish biological benchmarks from management reference points to ensure transparency in the relative influence of biological versus socioeconomic information in decision making.

Keymords: biological benchmarks, conservation, fisheries, Pacific salmon, reference points, resource management, sockeye salmon

\section{INTRODUCTION}

The boundary between policy and science is a topic of vigorous debate (Lackey 2007; Scott et al. 2007; Rice 2011), but the role of reference points at this interface has received comparatively little attention. In resource management, reference points can be based on scientific and/or socioeconomic information. Scientifically-based biological reference points have been widely adopted in fisheries management to categorize the status of fishery resources, often guiding management decisions (Collie \& Gislason 2001). Reference points commonly represent either maximum or target fishing mortality rates or minimum stock biomass levels, and are usually based on biological characteristics such as the number of spawners per adult recruit, surplus production, natural mortality or body growth (Collie \& Gislason 2001). Target reference points typically indicate levels of desirable stock status for management, whereas limit reference points indicate undesirable levels that management actions should seek to avoid (Caddy \& Mahon 1995).

For fisheries with multiple competing objectives, identifying and implementing target and limit reference points present various challenges. For instance, limit reference points are usually defined for populations or population aggregates, but may not consider the impact of reduced abundances on component populations, other populations/species (for example comigrating populations or predators) or ecosystem services, each of which may influence management decisions. This challenge will be especially relevant when population aggregates are managed as a whole, but contain component populations that are important sources of genetic diversity or colonists for depleted populations. Within-species diversity may be required for long-term viability of species (for example sockeye salmon; Levin \& Schiewe 2001; Hilborn et al. 2003; Schindler et al. 2010) and is important for maintaining ecological processes, which generally act at the population level (Wood \& Gross 2008). In addition, population sizes are generally estimated with error, and the structure and parameters of the models used to derive reference points are often uncertain. When those uncertainties are not

\footnotetext{
${ }^{*}$ Correspondence: Dr Carrie Holt e-mail: Carrie.Holt@dfo-mpo.gc.ca

The online version of this article is published within an Open Access environment subject to the conditions of the Creative Commons Attribution-NonCommercial-ShareAlike licence < http://creativecommons.org/licensesw/by-nc-sa/2.5/>. The written permission of Cambridge University Press must be obtained for commercial re-use.
} 
accounted for appropriately and communicated clearly, status assessments based on reference points may be overly confident and result in management advice that is not precautionary.

Furthermore, natural scientists are often tasked with identifying target reference points, but generally lack the training and expertise to articulate or quantify socioeconomic criteria required to determine management targets (Grafton et al. 2007). Based primarily on long-term criteria and more closely aligned with scientists' expertise, limit reference points set boundaries to avoid undesirable stock conditions associated with recruitment overfishing and unacceptable risks of population collapse (Restrepo 2001). Ambiguity in the definition of what is undesirable (whether it be, for example, probability of severe decline or loss of economic benefits from harvest), and uncertainty in the point estimate will add subjectivity, and provide opportunities to consider additional values that fall outside the scope of natural science. Indeed, limit reference points are sometimes designed to address both long-term objectives related to conservation and production, and shorter-term socioeconomic considerations. In those cases, a population may be above a limit reference point based on long-term biological criteria alone, but may be below a level that is economically efficient to harvest, suggesting an immediate need for management intervention.

Conversely, target and limit reference points defined for annual management plans may not provide guidance necessary for determining conservation status, which relies solely on biological data. Given recent concerns about loss of biodiversity, national and international management agencies now recognize the evaluation of conservation status (risk of extinction) as a priority. The International Union for Conservation of Nature (IUCN) provides the most widely used approach for assessing conservation status of plant and animal species, based on decline rates, population abundances, distribution and various other quantitative analyses. Thresholds in those criteria differentiate among threatened, endangered or critically endangered categories (Mace et al. 2008), and can be considered a special case of reference points used specifically to identify species at risk of extinction. In Canada, the evaluation of conservation status is legislated nationally by the Species At Risk Act (SARA, see URL http:// www.sararegistry.gc.ca/approach/act/default_e.cfm), and uses similar criteria and thresholds for status determination as IUCN (Irvine et al. 2005; COSEWIC [Committee on the Status of Endangered Species in Canada] 2011). One strength of the Canadian approach is the clear separation of scientific input used by COSEWIC from the Government of Canada's legal listing process, which considers social and economic as well as biological factors (Irvine et al. 2005; Mooers et al. 2010). Social and economic concerns can result in the Canadian government not legally listing species under SARA that were recommended for listing by COSEWIC (Irvine et al. 2005; Dawe \& Neis 2012).

Here we describe an approach for identifying reference points associated with long-term conservation and production objectives that is independent of short-term social, economic and political considerations. This does not mean that scientists do not provide input into management decisions, quite the contrary, but in this approach, the articulation of reference points categorizing long-term objectives is not influenced by socioeconomic factors that vary annually or across population units. We use the term biological benchmarks to identify those reference points that delimit zones of status corresponding to long-term conservation and production goals, such as the maintenance of genetic diversity. Biological benchmarks are generally distinct from reference points identified to reach management objectives that rely, at least in part, on socioeconomic considerations that are often short-term in nature. Although the identification of biological benchmarks may include conservation and production considerations, the intent is that they are void of social, economic or political considerations. Rigor is provided by the consistent application of these benchmarks over time and across populations.

The purpose of this paper is to illustrate how clear separation of objectives related to long-term conservation and production from those related to generally shorter-term socioeconomic concerns allows for more transparent and accountable decision making. We describe several differences between biological benchmarks and reference points in the context of marine fisheries, and provide a case study on wild Pacific salmon (Oncorhynchus spp.) in Canada. In the Fraser River (British Columbia, Canada), biological benchmarks have been identified to assess the biological status of sockeye salmon $(O$. nerka) and, in a separate process, management reference points have been developed for population aggregates considering biological status of component populations relative to biological benchmarks.

\section{DIFFERENCES BETWEEN BIOLOGICAL BENCHMARKS AND REFERENCE POINTS}

Most importantly, biological benchmarks and reference points differ in the information used to define them and the regulatory and legal implications of the resulting assessment. Although both biological benchmarks and reference points consider long-term objectives on conservation and production, management reference points generally require additional information on annual harvest and other socioeconomic considerations. In a scheme of considerations on long-term conservation and production goals and shorter-term socioeconomic considerations (Fig. 1), the long-term considerations influence biological benchmarks and management reference points, whereas shorter-term considerations influence reference points only. Stakeholders provide input on the development of reference points and contribute to management recommendations through interactive public consultations (Fig. 1). When status is assessed against reference points, the consequences are evaluated on biological, social and economic considerations in an open and transparent way, so that recommendations are accountable to those considerations (Fig. 1). In a review of four fishery case studies, Röckmann et al. (2012) 


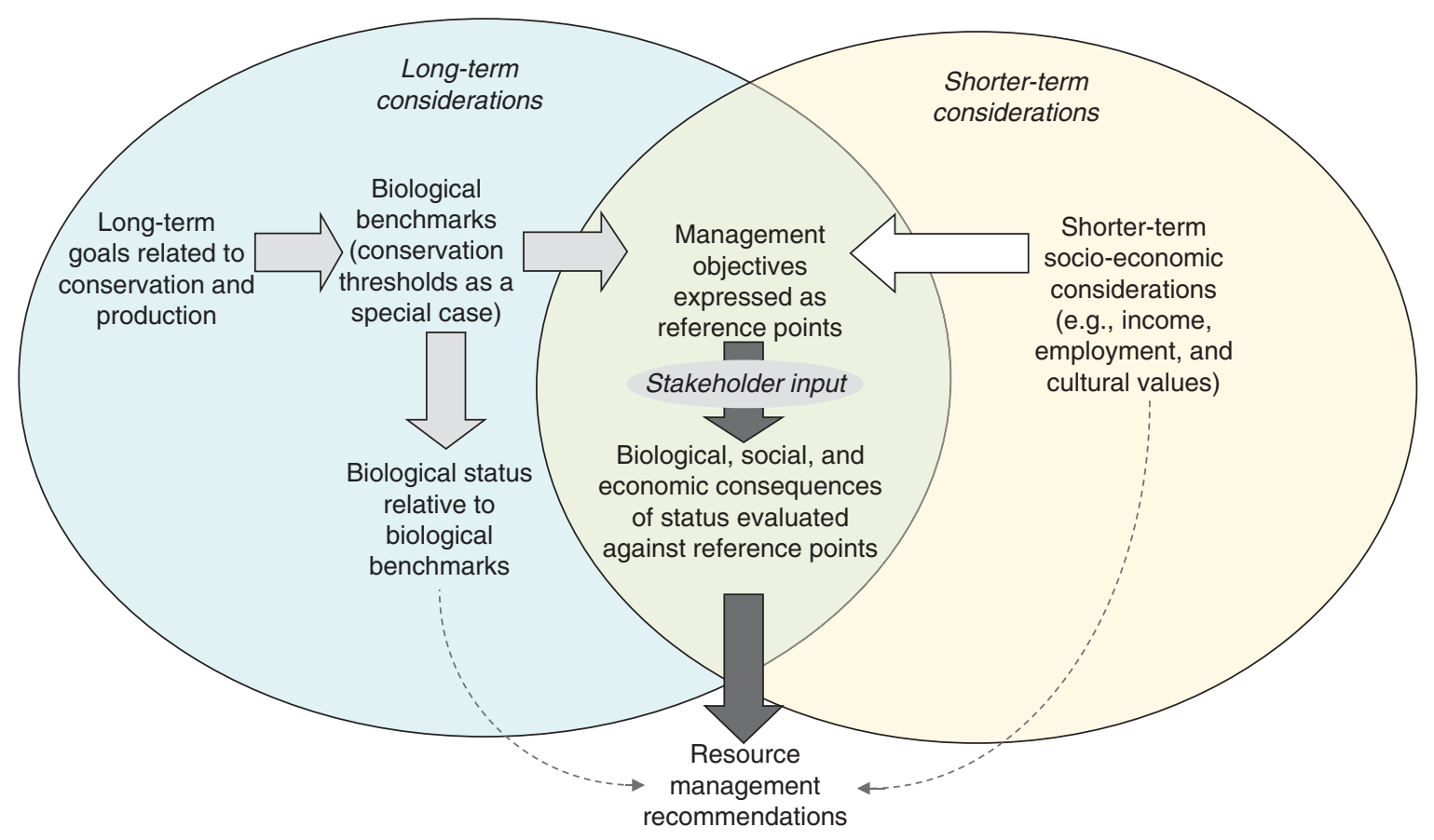

Figure 1 Schematic showing separate spheres of influence for long-term and shorter-term considerations on management decisions. Biological benchmarks are derived from long-term goals on conservation and production and inform biological status and management objectives (light grey arrows), while management reference points also use information on shorter-term socioeconomic considerations (white arrow). Reference points are identified in a transparent integrative process involving stakeholders (overlapping spheres of long-term and shorter-term considerations). Resource management recommendations are based on an evaluation of the biological, social and economic consequences of various management options. In this way, recommendations are accountable to (dashed lines) biological status relative to benchmarks and shorter-term socioeconomic considerations.

concluded that participation of stakeholders in the planning and execution of policies, including during the modelling process, contributed to collective learning, legitimacy and scientific understanding. Specifically concerning reference points, Gabriel and Mace (1999, p. 39) recommended that 'harvest control rules (including their component biological reference points) should be developed in the management planning stage with the involvement of all stakeholders', where the harvest control rule was a pre-agreed course of action depending on stock status, economic and/or environmental conditions. Similarly, Caddy and Defeo (2003) suggested public consultation when developing boundaries for the traffic light approach to management, in which multiple measures of stock status and fishery performance, including economic and social outcomes, were considered.

Incorporating stakeholders' input generally involves a structured decision-making process that identifies the most important concerns and the possible consequences of various actions (Gregory 2000). Derived from the fields of decision analysis and behavioural decision research, such approaches typically include five tasks: framing the decision, defining key objectives, establishing management alternatives (such as alternative reference points), identifying consequences, and clarifying trade-offs (Keeney \& Raiffa 1993). The primary goal of such approaches is to improve thinking and sharpen communication' about critical trade-offs among competing objectives (Gregory 2000, p. 35). Although group consensus is not assured (or in some cases, even necessary), structured decision making allows stakeholders to explore their own values and gain appreciation of others values, thereby enhancing trust and often increasing the acceptability of future decisions (Gregory 2000).

In addition to the types of information considered, reference points and biological benchmarks differ in the implications of the resulting status assessment. Reference points are linked to specific management responses, while biological benchmarks rarely prescribe specific actions. The Food and Agriculture Organization of the United Nations (FAO) Code of Conduct for Responsible Fishing (FAO 1995) states that fisheries management should determine the actions to be taken when target and limit reference points are met, in part to ensure that the level of fishing permitted is commensurate with the state of fisheries resources. The USA's Magnuson-Stevens Fishery Management and Conservation Act of 1996 (see URL http://www.habitat.noaa.gov/pdf/magnusonstevensact.pdf) requires by law that once a stock drops below an overfished threshold, plans be developed to rebuild the stock to biomasses associated with maximum sustainable yield $\left(B_{\mathrm{MSY}}\right)$, where overfished is defined as biomass at less than half of $B_{\mathrm{MSY}}$. As part of Canada's Sustainable Fisheries Framework, Fisheries and Oceans Canada (DFO) recommends the development of stock-specific harvest control rules based on the best information available, and provides provisional limit and upper reference points delineating healthy, cautious and 
critical zones (DFO 2009a). Although not enforced by law as in the USA, the Canadian Sustainable Fisheries Framework advises that fishery removal rates be reduced when stocks are depleted below upper reference points and be constrained to a minimum level below limit reference points (but note that reference points have not yet been identified for many harvested stocks in Canada; Hutchings et al. 2012). In contrast, poor status based on biological benchmarks does not prescribe specific management actions, as illustrated earlier in the previous example of COSEWIC and SARA.

Furthermore, biological benchmarks and reference points differ in their underlying assumptions. Biological benchmarks generally assume that population dynamics can be predicted from quantitative models, and the structure and parameters of models can be inferred from time-series of biological data. However, for data-poor populations, comprehensive timeseries of biological data are often not available. For some of those cases, alternative benchmarks that require relatively few data or borrow information from nearby populations have been developed (for example for Chinook salmon in British Columbia, Canada; Parken et al. 2006; Liermann et al. 2010). The specific assumptions required will depend on the biological benchmark and underlying population model.

Reference points that integrate stakeholder input require additional assumptions about human behaviour and decision making. When integrating stakeholders' preferences or decisions with outputs from biological models for example, those decisions are typically assumed to be 'bounded rational' (Schlüter et al. 2011). Rational decision-making has long been a principle of economic modelling that allows actors within the model to optimize well-being (for example by maximizing fishery harvest and/or minimizing the chance of population loss). However, imperfect knowledge, limited cognitive abilities, social networks, risk aversion and information exchange (or lack of) can result in decisions that deviate from rational expectations based on economic value (Schlüter et al. 2011). In particular, ambiguity due to vague, unspecific or context-specific language when communicating technical information such as biological assessments can result in stated preferences that deviate from true underlying values. This problem is exacerbated when communicating among stakeholders and disciplines with different worldviews and vocabularies (Regan et al. 2002). Indeed, research on the valuation of environmental goods shows that stated values are only fuzzily related to formal economic preferences (Bateman \& Mawby 2004). The consequences of making management decisions given uncertain stakeholder preferences is not well understood, though at least one study has shown that heterogeneity in stakeholder beliefs (due to, for example, heterogeneity in access to information) can cause irregular oscillations in the state of the ecosystem when stakeholder input is used to inform management decisions (Carpenter et al. 1999).

When identifying and implementing reference points, it is also assumed that harvesters will comply with harvest regulations and that reference points (and associated harvest regulations) can be implemented without error. However, it is widely recognized that regulatory control is imperfect because of lack of enforcement and/or the relationships between harvest control measures and desired outcomes are not well understood (Dichmont et al. 2006; Fulton et al. 2011). Furthermore, decision-makers may deliberately deviate from agreed upon reference points in response to immediate social or political pressures when faced with difficult options, such as closing a fishery (Dichmont et al. 2006; Holt \& Peterman 2006; Fulton et al. 2011).

Although not formally linked, there is some agreement in marine fisheries that limit reference points for management should be set above conservation thresholds that define an unacceptable probability of extinction (Powles et al. 2000). Therefore, the critical (unsafe) zone for fisheries management would contain an area of high risk of extinction, as well as an area where productivity is impaired but extinction risks are not high (Powles et al. 2000). Misalignments between management reference points and conservation thresholds are an issue of concern for agencies that are legally accountable to conservation status, but typically make annual fishery decisions based on management reference points (Dulvy et al. 2003; Davies \& Baum 2012).

\section{CASE STUDY ON CANADA'S WILD SALMON POLICY}

We demonstrate the distinction between biological benchmarks and management reference points with a case study on wild Pacific salmon in Canada, a multi-species resource of significant economic and social value (Bottom et al. 2009; Wild Salmon Center 2009) that has recently attracted attention due to conservation concerns about various populations (see Peterman \& Dorner 2012; Rand et al. 2012). We provide the example of sockeye salmon from the Fraser River to illustrate the independent processes of developing biological benchmarks and reference points for management, and how uncertainties are explicitly considered in the determination of both.

In 2005, Canada released the Wild Salmon Policy (WSP) that aimed to restore and maintain healthy and diverse salmon populations and their habitats for the benefit and enjoyment of the people of Canada in perpetuity (DFO 2005). Policy development overlapped with the proclamation of SARA that, as described earlier, separated COSEWIC's scientific input from the additional social and economic information used by the Government of Canada in determining whether a species should be legally listed under the SARA. DFO aligned the WSP with SARA as far as was practicable (Irvine \& Fraser 2008), including the separation of biological status information from additional social and economic information. The result was a transparent model (Millstone et al. 2008; Renn 2008), where scientists and non-scientists could collaborate in the traditionally scientific and non-scientific roles of risk assessment and risk management, respectively (Irvine 2009). While risk assessments quantify the probabilities and 
magnitudes of the consequences of a management action (for example by using simulation models that incorporate the random components inherent in natural and social systems), risk management involves subjective trade-offs among actions based on risk assessments and other considerations (Peterman 2004).

The WSP presents six strategies to achieve its goals, the first of which pertains to identification of biological status of conservation units (CUs) of salmon. CUs are populations of wild salmon sufficiently isolated from other populations that, if extirpated, are very unlikely to recolonize naturally within an acceptable timeframe, such as a human lifetime (DFO 2005). Biological benchmarks are used to identify population status by delineating three zones: red, amber and green (DFO 2005; Holt et al. 2009). The lower benchmark between red and amber represents a level of abundance high enough to ensure a substantial buffer above the level of abundance that could lead to a populations being considered at risk of extinction by COSEWIC. A status assessment in the red zone will initiate immediate consideration of ways to protect fish, increase their abundances and reduce the probability of loss, but will not prescribe specific fishery management actions. The upper benchmark between amber and green represents a level expected to provide, on an average annual basis, the maximum sustainable yield, below which production is reduced. Transparency in the consideration of uncertainties due to, for example, data quality and assumptions about population productivity, is a key principle in assessment and communication of biological status.

A multi-criteria approach was developed for assessing biological status under Strategy 1 of the WSP that uses information on current abundances, trends in abundance over time, the distribution of spawners, and fishing mortality relative to stock productivity. The approach captures the multiple dimensions of population status that will be important to achieve WSP goals, and recognizes the different types and qualities of data that are available among CUs (Holt et al. 2009). For spawner abundances in particular, candidate lower benchmarks drawn from the scientific literature were evaluated using a stochastic simulation model of population dynamics that accounted for observation errors in abundances, uncertainties in parameter estimates, and natural variability in adult recruitment and age-at-maturity. Performance was evaluated against two biological criteria; probability of extirpation over 100 years, and probability of recovery to spawner abundances that would maximize sustainable yield within one and three generations (Holt 2009, 2010; Holt \& Bradford 2011). The lower benchmark, spawner abundances that will result in recovery to $S_{\mathrm{MSY}}$ within one generation under equilibrium conditions $\left(S_{\text {gen }}\right)$, was selected because it performed well under the largest range of uncertainties, including variability in population productivity (Holt 2009; Holt \& Bradford 2011). While biological benchmarks on other metrics (such as trends in abundances over time and distribution of spawners) have been developed, the integration of information from multiple metrics into a single overall biological status has so far been limited (see for example Grant \& Pestal 2012).

The overall biological status is then combined with information on habitat quality and quantity (as identified in Strategy 2 of the WSP), ecosystem values that recognize salmon's ecological role in the ecosystem including interactions with other species (Strategy 3), and social and economic factors in an integrated strategic planning process (Strategy 4). Management options (including those related to fishery harvest, fish habitat, and enhancement activities) are then identified in a transparent consultative process that explicitly considers biological, habitat and ecosystem status, as well as social and economic factors (Strategy 5). For fisheries management in particular, annual management decisions are developed using decision-support tools, such as harvest control rules that use reference points, identified to meet biological and socioeconomic objectives with an adequate degree of confidence after accounting for uncertainty (DFO 2005). These strategies require transparency in how biological and socioeconomic information is weighted during the decision-making process. In this way, when poor status relative to biological benchmarks does not trigger management actions because of other overriding socioeconomic factors, biological status is clearly documented so that the implications of such decisions are understood. Furthermore, in accordance with FAO's Precautionary Approach to Fisheries (FAO 1996), transparency in the level of uncertainty when developing and implementing biological benchmarks and reference points means that lack of information should not be used to prioritize socioeconomic factors over long-term biological objectives.

One challenge when implementing the WSP is the possible incongruence between CUs and management units (Irvine \& Fraser 2008). For example, because sockeye salmon home precisely to spawning areas associated with geographically disjunct lakes, they exist as a relatively large number of reproductively and/or ecologically isolated CUs ( $>200$, province wide). However, because fisheries for sockeye salmon occur primarily in marine and estuarine areas where separate populations comingle, management has focused on mixedpopulation aggregates, resulting in a relatively small number of management units (49). In contrast, most pink salmon (O. keta) spawn and rear in the lower reaches of coastal rivers and exhibit only low levels of reproductive isolation among spawning areas, resulting in fewer CUs (32) that represent geographically larger areas than those for sockeye salmon. In some cases (for example southern British Columbia mainland inlets), pink salmon are managed, in part, as groups of fish that enter individual rivers to spawn, which results in more management units than CUs. Differences between CUs and management units result in challenges for managers who are accountable to biological status of CUs and fishery objectives for the management unit. If CUs are nested within management units, reference points on management units can be chosen to ensure biological objectives on component CUs are achieved. In contrast, if management units are nested within CUs or the units are not nested (if the management 
units and CUs partially overlap), care is required to ensure that management actions and reference points are coordinated to meet long-term biological objectives of CUs and shorterterm socioeconomic objectives of management units. Here we describe an application of biological benchmarks and reference points to a fishery on sockeye salmon returning to the Fraser River.

\section{Fraser River sockeye salmon}

Biological status was assessed for 24 CUs of sockeye salmon from the Fraser River watershed using a format that considered four sources of uncertainty: observation errors in abundances, and uncertainties in current population productivity, the structural form of the relationship between spawners and adult recruitment to the next generation, and parameter estimates (Grant et al. 2011; Grant \& Pestal 2012). Because of the multiple metrics and various population models and assumptions considered, multiple sets of benchmarks were identified for each $\mathrm{CU}$, providing a multi-dimensional evaluation of status. Status was integrated across metrics and model assumptions using expert opinion elicited in a workshop format (Grant \& Pestal 2012). Although technical expertise was drawn from a diverse group of stakeholders including academic researchers, government scientists, fisheries managers, Canadian Aboriginals, commercial and recreational fisheries representatives, and non-governmental organizations, experts were asked to provide objective scientific advice based on long-term conservation and production criteria, without introducing values derived from shorter-term social and economic objectives (Grant \& Pestal 2012).

In a separate process, for the 2010 fisheries on Fraser River sockeye salmon, four harvest control rules that included lower and upper reference points were developed for four management units, where each management unit is comprised of one or more CUs. Above the upper reference point, total allowable mortality (mortality due to fishing and other sources during return migration) was capped at $60 \%$, and below the lower reference point, it was set at a mortality rate floor near zero (Fig. 2). Between the lower and upper reference points, total allowable mortality was scaled to abundance. Reference points were selected to meet harvest and biological objectives, namely to minimize the probability of harvest dropping below a stakeholder-derived minimum, $C_{\mathrm{MIN}}$, while also minimizing the probability that component CUs, which are nested within the management unit, will drop below their lower biological abundance benchmarks (Pestal et al. 2011). In this case, biological benchmarks were limited to metrics on spawner abundances, and did not consider the multidimensional nature of biological status (for example metrics on trends in abundances over time or distribution of spawners). Candidate reference points for each of the four management units were evaluated in a stochastic simulation model that incorporated population dynamics of component CUs and harvest according to a decision rule that used a candidate set

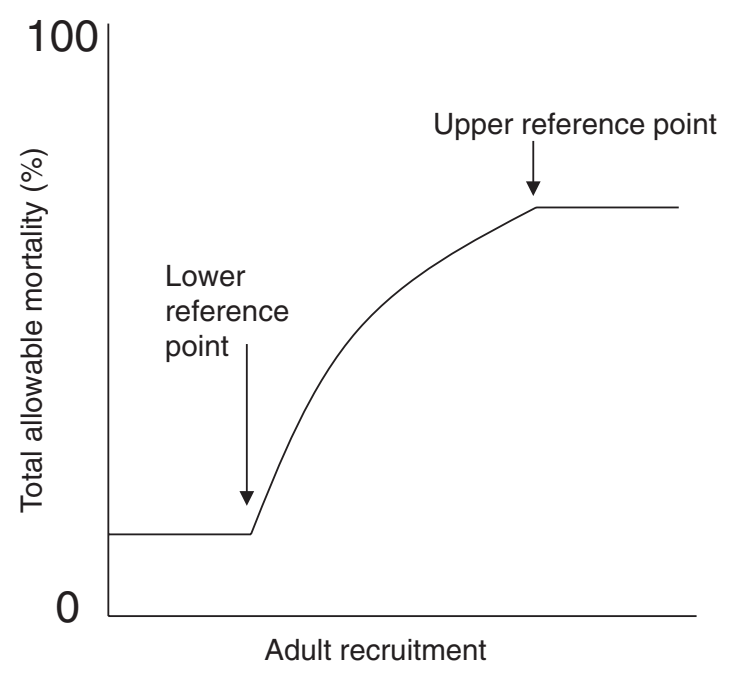

Figure 2 Example harvest rule for one management unit of Fraser River sockeye salmon that includes a lower and an upper reference point on adult recruitment (units omitted) (adapted from Pestal et al. 2011). Biological benchmarks are not applicable here because the management unit is made up of multiple assessment units (conservation units).

of lower and upper references points (see Fig. 2). Performance of candidate reference points was evaluated by the proportion of simulated years when management-unit catch dropped below $C_{\mathrm{MIN}}$ and the proportion of years when generational average abundances of individual CUs dropped below lower biological benchmarks, including sensitivity analyses to key model assumptions (Pestal et al. 2011).

In a series of collaborative workshops and consultations, stakeholders and managers integrated technical analyses with additional qualitative considerations on socioeconomic factors to select reference points for the annual management plan (Pestal et al. 2011). For example, for the 2010 fishery on the Early Summer Run management unit, candidate decision rules that differed in lower and upper reference points were provided for consultation, and the performance of those rules evaluated through simulation (Fig. 3) (DFO 2009b). When selecting among candidate reference points, managers and stakeholders were required to consider tradeoffs between the probability of catch dropping below $C_{\mathrm{MIN}}$ and the probability of spawner abundances of individual CUs dropping below lower biological benchmarks. In this example, the performance of the decision rule with a lower reference point equal to 120000 (and upper reference point $=300000)$ resulted in $<40 \%$ probability of low catches and $<15 \%$ probability of spawner abundances dropping below lower benchmarks for seven of the eight CUs, and was recommended for further consideration (A.-M. Huang, DFO, Fisheries Management Branch, Vancouver, BC, Canada, personal communication October 2012). Reference points were subsequently revised following additional stakeholder consultation on acceptable levels of risk (DFO 2010). The lower and upper reference points defined 


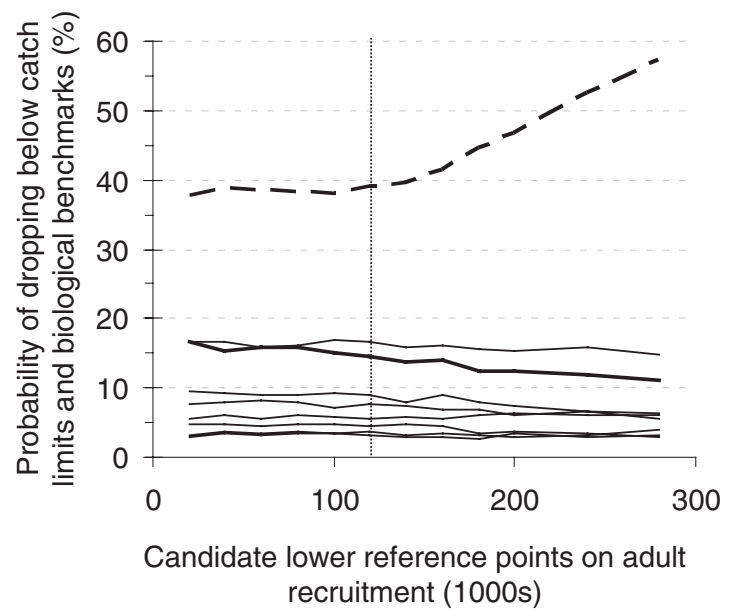

Figure 3 Probabilities of dropping below catch limits and biological benchmarks ( $y$-axis) for candidate lower reference points on adult recruitment ( $x$-axis) derived from a simulation model of population dynamics for the Early Summer Run management unit of Fraser River sockeye salmon. The dashed line is the probability of catches dropping below a stakeholder-derived minimum, $C_{\mathrm{MIN}}$, and the solid lines are the probabilities of generational mean spawner abundances for eight component conservation units (CUs) dropping below their lower biological benchmarks. Although performance against biological benchmarks is relatively constant for the range of reference points considered here, for one CU, Pitt River (thickest solid line), the probability of dropping below the biological benchmark declines with increases in the lower reference point. The vertical dotted line is the lower reference point that was recommended for further consideration by managers and stakeholders (adapted from DFO 2009b).

for Fraser River sockeye salmon are similar to limit and target reference points as defined by FAO (1995) in that both imply a management response when status is depleted below reference points. However, they differ in that limit and target reference points explicitly identify levels of abundance to be avoided and that are desired, respectively, whereas lower and upper reference points were selected for Fraser River sockeye salmon to achieve multiple, often conflicting objectives, but did not reflect management targets and limits in themselves.

The example of Fraser River sockeye salmon differentiates between biological benchmarks and management reference points in several ways. First, the determination of biological benchmarks is kept separate from the management process, ensuring the evaluation of status against long-term objectives is independent of socioeconomic considerations (as shown in Fig. 1). Second, the development of reference points explicitly accounts for the probability of low catches, which was not considered when identifying biological benchmarks. Third, biological benchmarks are estimated from spawner and adult recruitment data, and will be revised periodically (every generation, or approximately every four years) as new data become available to improve parameter estimates and respond to changes in intrinsic productivity that occur over generational time scales. In contrast, the intent of reference points is to provide a transparent basis for managing harvest that is consistent over time and relatively robust to changes in productivity. However in practice, reference points for Fraser River sockeye salmon have been updated in response to annual variability in stakeholder input due to a multiyear learning process and changes in management strategies corresponding to a relatively consistent four-year pattern in the abundances of some CUs ('cyclic CUs'). For example, in years when cyclic CUs are expected to return at low abundances, recommended reference points for management units that contain those CUs may be more precautionary (A.-M. Huang, DFO, Fisheries Management Branch, Vancouver, BC, Canada, personal communication October 2012).

While the choice of reference points reflects trade-offs between long-term biological objectives and shorter-term socioeconomic considerations, fine-tuning can occur during a fishing season. For instance, managers can adjust the timing and spatial distribution of fishing to reduce mortality on depleted CUs to reduce the probability that abundances will drop below lower biological benchmarks. During 2010, harvest was constrained at the beginning of the season to reduce fishery impacts on depleted CUs that migrate through fishing grounds earlier than more abundant CUs within the Early Summer Run management unit. However, exploitation rate floors as high as $10-30 \%$ were permitted on depleted CUs to allow harvest on comigrating CUs or management units in cases when decision rules provided only a near-zero total allowable mortality (DFO 2012). This provision was intended to allow some fishing on abundant comigrating CUs. In this instance, the biological implications of such harvest decisions can be clearly documented given current biological assessments.

\section{DISCUSSION}

The Fraser River sockeye case study demonstrates the distinction between biological benchmarks and management reference points, including the different processes required to develop them. Similarly, VanderZwaag et al. (2012) recommended distinguishing between science-determined reference points derived from scientific data and models (namely biological benchmarks) and science-based reference points that combine biological information with socioeconomic considerations in a consultation process. Hutchings and Rangeley (2011) recommended the same distinction when providing management advice for the recovery of depleted populations of Canadian Atlantic cod (Gadus morhua).

Canada's Wild Salmon Policy illustrates the similar methods that can be used to evaluate the performance of biological benchmarks and management reference points prior to implementation, despite differences in purpose. Under the WSP, candidate biological abundance benchmarks were identified and evaluated using stochastic simulation models 
that accounted for natural variability in adult recruitment and age-at-maturity and observation errors in abundances (Holt 2009; Holt \& Bradford 2011). In the example of Fraser River sockeye salmon, candidate decision rules and reference points were evaluated through stochastic simulation that accounted for natural variability in adult recruitment, mortality and runtiming of CUs (Pestal et al. 2011).

Although technically similar, the evaluation of biological benchmarks and management decision rules (and corresponding reference points) differed in the types of performance measures and the expert input required to review the models. While long-term viability and biological production were considered in the development of both biological benchmarks and management reference points, harvest objectives were only included in performance metrics on reference points (Pestal et al. 2011; Grant \& Pestal 2012). Differences in temporal scales of objectives and performance metrics (for example long-term production versus current harvest) are a common challenge in meeting diverse goals in resource management, which may be overcome by developing tools, such as the ones presented here, that explicitly consider the multiple scales over which fisheries and ecological populations occur, or which convert future value of conservation into net present value for managers (Salomon et al. 2011). Although the assessment of biological benchmarks and management decision rules both required biological expertise, the latter required additional stakeholder input to ensure objectives related to harvest were captured appropriately by model output and aligned with performance metrics.

Major changes in resource management take significant time. Development of the WSP took six years (Irvine 2009), and its implementation, begun in 2005, is ongoing. The case study illustrated a relatively recent implementation of reference points on Fraser River sockeye salmon; a thorough evaluation of the management and biological outcomes of the separation of long-term objectives from short-term socioeconomic concerns has not yet been completed. In the future, we hope to see clearly articulated limit and target reference points that consider the multidimensional nature of biological, social and economic information.

The concept of biological benchmarks can be broadened from the status of single populations to include species interactions and ecosystem considerations. Ecosystem objectives can contribute to the identification of management recommendations in the same way as long-term conservation and production, and socioeconomic objectives (Fig. 1). Identifying multi-species or ecosystem benchmarks and objectives will require input from diverse fields of expertise and resource sectors. Furthermore, ecosystem reference points and the indicators on which they are based can be developed in relation to the population sizes of a species of interest, population trends, community composition, and energy or material flow (Kershner et al. 2011). Multiattribute ecosystem-based control rules for fisheries can be identified when ecosystem indicators are related to fishery-induced changes (see Link 2005), but despite recent progress implementing an ecosystem-approach to fisheries management (Hollowed et al. 2011; Link et al. 2011), the application of such control rules is rare. One, often paralysing challenge in making management decisions that account for the multi-dimensional nature of ecosystem dynamics is reaching consensus among diverse interests and conflicting objectives. Viability theory provides a promising solution by identifying management options that are 'viable' (namely above limit reference points) on all indicators, an option that is often easier to identify than optimization on indicators (or above target reference points) (Cury et al. 2005). For example, in the Southern Benguela ecosystem, Mullon et al. (2004) used an ecosystem model with interacting physical, biological and harvest components to identify a viable kernel containing all possible combinations of five ecosystem indicators that were above acceptable levels. Similar methods may be applied to individual species when integrating multiple indicators of population status or providing management advice from numerous conflicting objectives.

Scientists have choices in the role they play in policy development (Pielke 2007). We encourage other agencies to differentiate between scientific information on biological status and socioeconomic information in decision making, as occurs in Canadian species-at-risk legislation, and increasingly, in the management of Pacific salmon. Separation reduces the likelihood of an inappropriate influence of advocacy on scientific advice (Lackey 2007; Rice 2011), and provides accountability of management decisions to biological status. Differentiating between biological benchmarks and management reference points allows for more transparency in decision making, and effectively improves the integration of science and policy.

\section{CONCLUSIONS}

In resource management, distinguishing benchmarks of biological status from management reference points effectively separates long-term conservation and production objectives from shorter-term socioeconomic goals. This approach, being used increasingly for the management of Pacific salmon in Canada, results in improved transparency in the decision making process, for instance when shorter-term harvest considerations are given priority over conservation concerns in management decisions. We encourage other resource management agencies to adopt this approach.

\section{ACKNOWLEDGEMENTS}

S.P. Cox, J.A. Hutchings, J. Schweigert, and C. Wood provided insightful comments on previous versions of the manuscript that resulted in significant improvements. Thanks to S. Grant, A.-M. Huang, and G. Pestal, for their useful input to the manuscript and for contributing data and expertise on 
Fraser River sockeye salmon, and L. Fitzpatrick for editorial assistance.

\section{References}

Bateman, I.J. \& Mawby, J. (2004) First impressions count: interviewer appearance and information effects in stated preference studies. Ecological Economics 49: 47-55.

Bottom, D.L., Jones, K.K., Simenstad, C.A. \& Smith, C.L. (2009) Reconnecting social and ecological resilience in salmon ecosystems. Ecology and Society 14: 5 [www document]. URL http://www.ecologyandsociety.org/vol14/iss1/art5/

Caddy, J.F. \& Defeo, O. (2003) Enhancing or restoring the productivity of natural populations of shellfish and other marine invertebrate resources. FAO Fisheries Technical Paper 448, FAO, Rome, Italy.

Caddy, J.F. \& Mahon, R. (1995) Reference points for fisheries management. FAO Fisheries Technical Paper 347, FAO, Rome, Italy.

Carpenter, S.R., Brock, W. \& Hanson, P. (1999) Ecological and social dynamics in simple models of ecosystem management. Ecology and Society 3(2): 4 [www document]. URL http://www.consecol.org/vol3/iss2/art4/

Collie, J.S. \& Gislason, H. (2001) Biological reference points for fish stocks in a multispecies context. Canadian Fournal of Fisheries and Aquatic Sciences 58: 2167-2176.

COSEWIC (2011) COSEWIC's Assessment Process and Criteria [www document]. URL http://www.cosewic.gc.ca

Cury, P.M., Mullon, C., Garcia, S.M. \& Shannon, L.J. (2005) Viability theory for an ecosystem approach to fisheries. ICES Fournal of Marine Science 62: 577-584.

Davies, T.D. \& Baum, J.K. (2012) Extinction risk and overfishing: reconciling conservation and fisheries perspectives on the status of marine fishes. Scientific Reports 2(561) doi: 10.1038/srep00561.

Dawe, J.L. \& Neis, B. (2012) Species at risk in Canada: lessons learned from the listing of three species of wolfish. Marine Policy 36: 405-413.

DFO (2005) Canada's Policy for the Conservation of Wild Pacific Salmon [www document]. URL http://www.pac.dfompo.gc.ca/fm-gp/species-especes/salmon-saumon/wsp-pss/ index-eng.htm

DFO (2009a) Fishery decision-making framework incorporating the precautionary approach [www document]. URL http:// www.dfo-mpo.gc.ca/fm-gp/peches-fisheries/fish-ren-peche/ sff-cpd/precaution-eng.htm

DFO (2009b) Fraser sockeye escapement strategy 2009: model overview and summary of 2009 planning simulations. Report prepared for Fisheries and Oceans Canada [www document]. URL http://www.pac.dfo-mpo.gc.ca/consultation/fisheriespeche/smon/docs/ifmp-pgip/2009/2009-fses.pdf

DFO (2010) Pacific Region integrated fisheries management plan. Salmon Southern BC June 1, 2010 to May 31, 2011 [www document]. URL http://www.dfo-mpo.gc.ca/Library/ 341187.pdf

DFO (2012) Pacific Region integrated fisheries management plan. Salmon Southern BC June 1, 2012 to May 31, 2013 [www document]. URL http://www.pac.dfo-mpo.gc.ca/fmgp/mplans/2012/smon/smon-sc-cs-2012-eng.pdf

Dichmont, C.M., Deng, A.R., Punt, A.E., Venables, W. \&. Haddon, M. (2006) Management strategies for short-lived species: the case of Australia's Northern Prawn Fishery. 1. Accounting for multiple species, spatial structure and implementation uncertainty when evaluating risk. Fisheries Research 82: 204-220.

Dulvy, N.K., Sadovy, Y. \& Reynolds, J.D. (2003) Extinction vulnerability in marine populations. Fish and Fisheries 4: 25-64.

FAO (1995) Code of Conduct for Responsible Fisheries. FAO, Rome, Italy [www document]. URL http://www.fao.org/ docrep/005/v9878e/v9878e00.htm

FAO (1996) Precautionary approach to capture fisheries and species introductions. FAO, Rome, Italy [www document]. URL http://www.fao.org/docrep/003/W3592E/W3592E00.htm

Fulton, E.A., Smith, A.D.M., Smith, D.C. \& van Putten, I.E. (2011) Human behaviour: the key source of uncertainty in fisheries management. Fish and Fisheries 12: 2-17.

Gabriel, W.L. \& Mace, P.M. (1999) A review of biological reference points in the context of the precautionary approach. In: Proceedings of the 5th National Marine Fisheries Service Stock Assessment Workshop: Providing Scientific Advice to Implement the Precautionary Approach Under the Magnuson-Stevens Fishery Conservation and Management Act, ed. V. Restrepo, pp. 34-45. US Department of Commerce, NOAA Technical Memorandum NMFS-F/SPO-40, USA.

Grafton, R.Q., Kompas, T., McLoughlin, R. \& Rayns, N. (2007) Benchmarking for fisheries governance. Marine Policy 31: 470479.

Grant, S.C.H. \& Pestal, G. (2012) Integrated biological status assessments under the Wild Salmon Policy using standardized metrics and expert judgement: Fraser River sockeye salmon (Oncorhynchus nerka) case studies. Canadian Science Advisory Secretariat Research Document 2012/106 (in press).

Grant, S.C.H., MacDonald, B.L., Cone, T.E., Holt, C.A., Cass, A., Porszt, E.J., Hume, J.M.B, \& Pon, L.B. (2011) Evaluation of uncertainty in Fraser sockeye (Oncorhynchus nerka) Wild Salmon Policy status using abundance and trends in abundance metrics. Canadian Science Advisory Secretariat Research Document 2011/087 [www document]. URL http://www.dfo-mpo.gc.ca/csassccs/Publications/ResDocs-DocRech/2011/2011_087-eng.html

Gregory, R. (2000) Using stakeholder values to make smarter environmental decisions. Environment 42: 34-44.

Hillborn, R., Quinn, T.P., Schindler, D.E. \& Rogers, D.E. (2003) Biocomplexity and fisheries sustainability. Proceedings of the National Academy of Sciences USA 100: 6564-6568.

Hollowed, A.B., Aydin, K.Y., Essington, T.E., Ianelli, J.N., Megrey, B.A., Punt, A.E. \& Smith, A.D.M. (2011) Experience with quantitative ecosystem assessment tools in the northeast Pacific. Fish and Fisheries 12: 189-208.

Holt, C.A. (2009) Evaluation of benchmarks for conservation units in Canada's Wild Salmon Policy: technical documentation. Canadian Science Advisory Secretariat Research Document 2009/059 [www document]. URL http://www.dfo-mpo.gc.ca/csassccs/publications/resdocs-docrech/2009/2009_059-eng.htm

Holt, C.A. (2010) Will depleted populations of Pacific salmon recover under persistent reductions in survival and catastrophic mortality events? ICES Journal of Marine Science 67: 2018-2026.

Holt, C.A. \& Bradford, M.J. (2011) Evaluating benchmarks of population status for Pacific salmon. North American Fournal of Fisheries Management 31: 363-378.

Holt, C.A. \& Peterman, R.M. (2006) Missing the target: implementation uncertainties in fisheries on Fraser River, British Columbia, sockeye salmon (Oncorhynchus nerka). Canadian fournal of Fisheries and Aquatic Sciences 63: 2722-2733. 
Holt, C.A., Cass, A., Holtby, B. \& Riddell, B. (2009) Indicators of status and benchmarks for conservation units in Canada's Wild Salmon Policy. Canadian Science Advisory Secretariat Research Document 2009/058 [www document]. URL http://www.dfompo.gc.ca/csas-sccs/publications/resdocs-docrech/2009/2009_ 058-eng.htm

Hutchings, J.A. \& Rangeley, R.W. (2011) Correlates of recovery for Canadian Atlantic Cod (Gadus morhua). Canadian Fournal of Zoology 89: 386-400.

Hutchings, J.A., Côté, I.M., Dodson, J.J., Fleming, I.A., Jennings, S., Mantua, N.J., Peterman, R.M., Riddell, B.E., Weaver, A.J., \& VanderZwaag, D.L. (2012) Is Canada fulfilling its obligations to sustain marine biodiversity? A summary review, conclusions, and recommendations. Environmental Reviems 20: 353361.

Irvine, J.R. (2009) The successful completion of scientific public policy: lessons learned while developing Canada's Wild Salmon Policy. Environmental Science and Policy 12: 140-148.

Irvine, J.R. \& Fraser, G.A. (2008) Canada's Wild Salmon Policy and the maintenance of diversity. American Fisheries Society Symposium 49: 391-398.

Irvine, J.R., Gross, M.R., Wood, C.C., Holtby, L.B., Schubert, N.D. \& Amiro, P.G. (2005) Canada's Species at Risk Act: an opportunity to protect 'endangered' salmon. Fisheries 30: 11-19.

Keeney, R.L. \& Raiffa, H. (1993) Decisions with Multiple Objectives: Preferences and Value Tradeoffs. Cambridge, UK: Cambridge University Press.

Kershner, J., Samhouri, J.F., James, C.A. \& Levin, P.S. (2011) Selecting indicator portfolios for marine species and food webs: a Puget Sound case study. PLoS ONE 6(10): e25248. doi:10.1371/journal.pone. 0025248

Lackey, R.T. (2007) Science, scientists, and policy advocacy. Conservation Biology 21: 12-17.

Levin, P.S. \& Schiewe, M.H. (2001) Preserving salmon biodiversity. American Scientist 89: 220.

Liermann, M.C., Sharma, R., \& Parken, C.K. (2010) Using accessible watershed size to predict management parameters for Chinook salmon, Oncorhynchus tshamytscha, populations with little or no spawner-recruit data: a Bayesian hierarchical modelling approach. Fisheries Management and Ecology 17: 40-51.

Link, J.S. (2005) Translating ecosystem indicators into decision criteria. ICES Journal of Marine Science 62: 569-576.

Link, J.S., Bundy, A., Overholtz, W.J., Shackell, N., Manderson, J., Duplisea, D., Hare, J., Koen-Alonso, M. \& Friedland, K.D. (2011) Ecosystem-based fisheries management in the Northwest Atlantic. Fish and Fisheries 12: 152-170.

Mace, G.M., Collar, N.J., Gaston, K.J., Hilton-Taylor, C., Akçaya, H.R., Leader-Williams, N., Milner-Gulland, E.J., \& Stuart, S.N. (2008). Quantification of extinction risk: IUCN's system for classifying threatened species. Conservation Biology 22: 14241442.

Millstone, E., van Zwanenberg, P., Levidow, L., Spök, A., Hirakawa, H. \& Matsuo, M. (2008) Risk-assessment policies: differences across jurisdictions. European Commission, Joint Research Centre, Institute for Prospective Technological Studies [www document]. URL http://ipts.jrc.ec.europa.eu/ publications/pub.cfm?id=1562

Mooers, A.O., Doak, D.F., Findlay, C.S., Green, D.M., Grouios, C., Manne, L.L., Rashvand, A., Rudd, M.A. \& Whitton, J. (2010) Science, policy, and species at risk in Canada. Bioscience 60: 843849.
Mullon, C., Cury, P., \& Shannon, L. (2004) Viability model of trophic interactions in marine ecosystems. Natural Resource Modeling 17: 71-102.

Parken, C.K., McNicol, R.E. \& Irvine, J.R. (2006) Habitat-based methods to estimate escapement goals for data limited Chinook salmon stocks in British Columbia, 2004. Canadian Science Advisory Secretariat Research Document 2006/083. URL http://www.dfo-mpo.gc.ca/csas-sccs/publications/resdocsdocrech/2006/2006_083-eng.htm

Pestal, G., Huang, A.-M., Cass, A.J. \& the FRSSI Working Group (2011) Updated methods for assessing harvest rules for Fraser River sockeye salmon (Oncorhynchus nerka). Canadian Science Advisory Secretariat Research Document 2011/133. URL http://www.dfo-mpo.gc.ca/csassccs/Publications/ResDocs-DocRech/2011/2011_133-eng.html

Peterman, R.M. (2004) Possible solutions to some challenges facing fisheries scientists and managers. ICES Journal of Marine Science 61: 1331-1343.

Peterman, R.M. \& Dorner, B. (2012) A widespread decrease in productivity of sockeye salmon (Oncorhynchus nerka) populations in western North America. Canadian Fournal of Fisheries and Aquatic Sciences 69: 1255-1260.

Pielke Jr, R.A. (2007) The Honest Broker. Making Sense of Science in Policy and Politics. Cambridge, UK: Cambridge University Press.

Powles, H., Bradford, M.J., Bradford, R.G., Doubleday, W.G., Innes, S. \& Levings, C.D. (2000) Assessing and protecting endangered marine species. ICES Fournal of Marine Science 57: 669-676.

Rand, P.S., Goslin, M., Gross, M.R., Irvine, J.R., Augerot, X., McHugh, P.A. \& Bugaev, V.F. (2012) Global assessment of extinction risk to populations of sockeye salmon Oncorhynchus nerka. PLoS ONE 7(4): e34065. doi:10.1371/journal.pone.0034065

Regan, H.M., Colyvan, M. \& Burgman, M.A. (2002) A taxonomy and treatment of uncertainty for ecology and conservation biology. Ecological Applications 12: 618-628.

Renn, O. (2008) Risk Governance: Coping with Uncertainty in a Complex World. London, UK: Earthscan.

Restrepo, V.R. (2001) Intersessional Meeting 2000 of the Coordinating Working Party: Working Group on Precautionary Approach Terminology. International Commission for the Conservation of Atlantic Tunas, Collective Volume of Scientific Papers 52(5): 1858-1860.

Rice, J.C. (2011) Advocacy science and fisheries decision-making. ICES fournal of Marine Science 68: 2007-2012.

Röckmann, C., Ulrich, C., Dreyer, M., Bell, E., Borodzicz, E., Haapasaari, P., Hauge, K.H., Howell, D., Mäntyniemi, S., Miller, D., Tserpes, G. \& Pastoors, M. (2012) The added value of participatory modelling in fisheries management: what has been learnt? Marine Policy 36: 1072-1085.

Schindler, D.E., Hilborn, R., Chasco, B., Boatright, C.P., Quinn, T.P., Rogers, L.A. \& Webster, M.S. (2010) Population diversity and the portfolio effect in an exploited species. Nature 465: 609612.

Schlüter, M., McAllister, R.R.J., Arlinghaus, R., Bunnefeld, N., Eisenack, K, Holker, F., Milner-Gullandm, E.J. \& Muller, B. (2011) New horizons for managing the environment: a review of coupled social-ecological modeling. Natural Resource Modeling 25: 219-272.

Scott, J.M., Rachlow, J.L., Lackey, R.T., Pidgorna, A.B., Aycrigg, J.L., Feldman, G.R., Svancara, L.K., Rupp, D.A., Stanish, D.I. \& Steinhorst, R.K. (2007) Policy advocacy in science: 
prevalence, perspectives, and implications for conservation biologists. Conservation Biology 21: 29-35.

Salomon, A.K., Gaichas, S.K., Jensen, O.P., Agostini, V.N., Sloan, N.A., Rice, J., McClanahan, T.R., Ruckelshaus, M.H., Levin, P.S., Dulvy, N.K. \& Babcock, E.A. (2011) Bridging the divide between fisheries and marine conservation science. Bulletin of Marine Science 87: 251-274.

VanderZwaag, D.L., Hutchings, J.A., Jennings, S. \& Peterman, R.M. (2012) Canada's international and national commitments to sustain marine biodiversity. Environmental Reviems 20: 312 352.

Wild Salmon Center (2009) North Pacific salmon fisheries economic measurement estimates [www document]. URL http:// www.wildsalmoncenter.org/pdf/Salmon_Economic_Valuation. pdf

Wood, C.C. \& Gross, M.R. (2008) Elemental conservation units: communicating extinction risk without dictating targets for protection. Conservation Biology 22: 36-47. 